\title{
The Truth About Health and Alcohol
}

\author{
James McIntosh
}

\begin{abstract}
The paper discussed here claimed that the old guidelines for safe alcohol consumption should be replaced by much lower ones of about one standard drink per day. However the paper suffers from some statistical problems which lead to misleading results. In addition, by concentrating on mortality and older members of the population it fails to account for important aspects of the effect of alcohol use on individual health. It is shown when the effects of alcohol use on self-reported health and health service utilization are considered what has been traditionally been proposed as safe drinking behavior should continue to be used.
\end{abstract}

Index Terms - Alcohol use, Longitudinal studies, Duration models, Hazard functions, self-reported health, Doctor visits, ordered probability models, Diabetes. and Stroke.

\section{INTRODUCTION}

In a recent paper in the Lancet Wood et al (2018) announced the following result

'In current drinkers of alcohol in high-income countries, the threshold for lowest risk of all-cause mortality was about $100 \mathrm{~g} /$ week. For cardiovascular disease subtypes other than myocardial infarction, there were no clear risk thresholds below which lower alcohol consumption stopped being associated with lower disease risk. These data support limits for alcohol consumption that are lower than those recommended in most current guidelines' (page 513). ${ }^{1}$.

This study is a meta-study of 83 prospective studies involving data from 19 high income European countries and it has 111 authors. It would be surprising if a study of this magnitude with its involvement with so many established scholars produced results which were contentious or possibly inaccurate. However, this is in fact what happens. The study suffers from a number of statistical faults and what is more important its main focus neglects important issues in the role that alcohol use plays in individual and public health.

These two themes will be explored in detail below. In the section on statistical methodology three problems are noted. These are a failure to account for the presence of competing risk biases in the analysis of terminal outcomes involving coronary heart and cardio-vascular disease, the inclusion of self-reported health variables as regressors in all-cause mortality results, and the failure to properly deal with

Published on 8 July, 2019.

Economics Department, Concordia University, 1455 de Maisonneuve Blvd. W. Montreal H3G 1M8, Quebec, Canada.

${ }^{1}$ I wish to acknowledge some advice given to me by Astrid James, a coeditor of the Lancet. As is customary in academia, comments, especially if they are critical of a paper, are first sent to the journal where the paper was published. My comments were rejected by the Lancet and I was advised to publish my results elsewhere. The Lancet offered no opinion on the validity or relevance of what I said about the Wood et al paper. I also as a courtesy sent a draft of the paper to Wood. She did not respond. unobservables.

While it is appropriate to examine the effects of alcohol use on all-cause mortality and other specific mortalities it is quite wrong to do this at the expense of other measures of health. The authors of this paper exclude any consideration of some non-mortality criteria that are clearly important in the assessment of the effects of alcohol on health like the utilization of the health services or how individuals actually rate their health in relation to their drinking behaviour. In addition, the analysis of the effects of alcohol use on diabetes, a disease which is quite debilitating in its own right and whose prevalence has been shown to be inversely related to moderate alcohol is missing from their analysis.

\section{STATISTICAL IsSUES}

There are two procedures which can be used to determine whether a particular type of behaviour affects lifetime durations; these are all-cause mortality models and competing risk models. Any other procedure, such as the common practice of trying to associate a particular type of behavior with the life durations of those who die from a particular disease is invalid. Papers like Harriss et al (2006) on the effects alcohol consumption on life durations of those who die of coronary heart disease represent a prominent example. In this example whether a person dies from coronary heart disease will be in part determined by other possible causes of death. If life durations from these causes are influenced by alcohol consumption the measured effect of alcohol consumption on the length of life of those who die from coronary heart disease will be biased. This is called competing risk bias and the possible consequences of this were first noted in McIntosh (2014a). That paper showed that considerable distortions could arise if the effects of alcohol consumption on life time durations due to other causes were not included in the analysis. Consequently, the results on fatal events in the lower right hand panel of Figure 2 in the paper should be regarded with caution.

The regressors used to explain outcomes contain a selfreported health variable. As is shown below and in a series of papers on Canadian health, McMin et al (2006) and McIntosh (2008), (2009), (2014a), (2014b), (2014c) and (2017)) alcohol use has a large impact on how individuals perceive their health status. The fact that alcohol use is a significant determinant of the self-reported health variables means that their inclusion in a model life time duration will reduce both the size and significance of the alcohol variables in these models. In the analysis of doctor visits discussed in the next section it is shown that the reduction in the coefficients associated with the frequency of drinking alcohol caused by including self-reported health varies from 30 to 60 percent. This is a substantial change and suggests that hazard ratios reported in the Wood study could be 
equally effected ${ }^{2}$.

It is also interesting to note that other studies which do not employ self-reported health as a regressor find hazard ratio minima or reversion points which are much higher than the 90 grams per week that the Wood study claims as an ideal consumption level. DiCastelnuovo et al (2006) show that for most scenarios there is no relative harm in drinking up to 210 grams per week. Baer et al (2010) find that approximately the same consumption level produces the lowest hazard ratio and Bergmann et al (2011: Figures 3\&4) show that there are no relative risks of CHD or CVD from any level of alcohol consumption.

Unobservables play an important role in determining health outcomes. It is important to be able to capture their effects by introducing a random effect into the models ${ }^{3}$. In the duration models considered in the Wood study there is an important unobservable variable and that is the difference between alcohol use at baseline and that when the agent died or had a first occurrence of a major health event such as a heart attack or a stroke. One way of dealing with this problem is to apply latent class analysis which allows for a typology for individual agents; in this case the classes are type 1: those whose drinking behavior has not changed since baseline and type 2 for those who have. This idea is explained more fully in McIntosh (2014b). Each type will have different regression coefficients associated with the variables which measure the effects of alcohol on the outcome in question.

Even if this is not a problem it is possible that the population is heterogeneous and different types react to alcohol use differently. All of the models considered in the next section required at least two latent classes to explain the data.

\section{VARIABLES OF INTEREST}

The focus of the Wood study is mainly on mortality and is based on cohorts who were aged around 55 at the beginning of the studies evaluated. Of course, these are important cohorts and length of life is an important consideration in the determination of the costs and benefits of alcohol use. However, it is also important to deal with diseases that that are not fatal but affect the health of the living population. No consideration was given to diabetes as a health problem. This is the one disease for which the medical research community almost unanimously finds that a very broad range alcohol use reduces the probability of contracting it. Some of the classic papers to report this are Buelens et al (2102), Pietraszek et al (2010), and McIntosh (2014c) for Canada. The benefits of lower risks of diabetes that accrue to all age groups from moderate alcohol use also need to be considered in the larger picture in which the

\footnotetext{
${ }^{2}$ This could be a result of simultaneous equation bias since the selfreported health variables are endogenous. See Greene (2008: 355) for a discussion of this problem.

${ }^{3}$ Heckman and Singer (1984: 271) note 'In every microeconomic study in which the hypothesis of heterogeneity is subject to test, it is not rejected. Temporally persistent unobserved components are an empirically important fact of life in microeconomic data (Heckman [19]). Since the appearance of papers by ..... social scientists have been aware that failure to adequately control for population heterogeneity can produce severe bias in structural estimates of duration models'.
}

benefits of alcohol use are evaluated.

The study did consider the effects of alcohol use on nonfatal episodes of cardiovascular disease but not for younger cohorts. There is substantial evidence that many diseases are less likely to occur among regular drinkers for younger members of the population. See for example, McIntosh (2017).

More importantly, there are other dimensions to this issue which are not considered. These are discussed below.

\section{SELF-REPORTED HEALTH AND DOCTOR VISITS FOR CANADA 2013-14}

Two important measures of individual welfare which are valid for all age groups are self-reported health ${ }^{4}$ and the number of times the individual utilizes the health service by going to a local health clinic or having a consultation with a family doctor. In Canada the proportion of the drinking age population under 55 is almost $56 \%$, a majority. That these younger cohorts are not considered in the Wood study and play no role is assessing the costs and benefits of alcohol consumption is a major shortcoming of the study.

Both of these variables indicate the current health status of the individual but there is an added social dimension to doctor visits and that involves the cost to society as a whole that individuals impose by consuming publically provided health care services. These costs are both financial and social when they increase the congestion in the health system. As will be shown below both of these variables have significantly better outcomes associated with frequent alcohol use.

The data employed in the analysis of these two variables comes from the 2013-2014 Canadian Community Health Surveys (CCHS). Unlike the Wood study which is based on longitudinal surveys the data comes from a sample and there is information on the respondents for only one point in time. Using this type of data is somewhat unusual and almost all of the research in this area has avoided using sample survey data. The reason why this is the case is the perception that the procedure is flawed since current data is being used to explain events which occurred in the past and is not seen as a very appealing methodology. However, as was shown in McIntosh (2014c) alcohol consumption on average is very stable across time and over cohorts so current alcohol consumption is a very good representation of life-time consumption for most individuals ${ }^{5}$. There will be some respondents for which this is not true and the latent class procedure mentioned earlier that was used to deal with unobservable differences between baseline and future alcohol consumption can be used to deal with the unobservable differences between current and life-time differences.

The measure of alcohol consumption, the monthly frequency of alcohol use is also unusual, although it has been considered favorably by Britton and Marmot (2003) in

\footnotetext{
${ }^{4}$ For a review of the reliability of self-reported health as a welfare measure see Idler and Benyamini (1997).

${ }^{5}$ Canada is not the only country with almost constant drinking behavior over time. This is also true for the United States. Data from the National Health Interview Survey show no change in the drinking status distribution between the years 2017 and 2007.
} 
addition to the volume of alcohol consumed. The categories are no drinks in the last 12 months, less than once a month, up to drinking every day. Doctor visits by drinking frequency, age group and gender are shown in Table 1.

While the CCHS has information for both variables there are significantly fewer observations on drinks per day or drinks per week and it is not clear that selection of respondents for which there is information on both types of variable is randomly determined. However, some use will be made of alcohol consumption per week.

TABLE I: NUMBER OF DOCTOR VISITS BY FREQUENCY OF DRINKING CATEGORY, AGE GROUP, AND GENDER

\begin{tabular}{|c|c|c|c|c|c|c|}
\hline \multirow{2}{*}{$\begin{array}{c}\text { Frequency of } \\
\text { Drinking }\end{array}$} & \multicolumn{3}{|c|}{ Male Age Groups } & \multicolumn{3}{|c|}{ Female Age Groups } \\
\hline & $30-49$ & $50-69$ & $70+$ & $30-49$ & $50-69$ & $70+$ \\
\hline $\begin{array}{l}\text { 0. None in last } \\
12 \text { months }\end{array}$ & 2.498 & 3.3093 & 3.902 & 3.185 & 3.658 & 3.665 \\
\hline $\begin{array}{l}\text { 1. Less than once } \\
\text { a month }\end{array}$ & 2.445 & 3.1843 & 3.639 & 3.382 & 3.244 & 3.463 \\
\hline 2. Once a month & 1.860 & 2.6852 & 3.269 & 2.802 & 2.957 & 3.195 \\
\hline $\begin{array}{l}\text { 3. } 2 \text { to } 3 \text { times a } \\
\text { month }\end{array}$ & 1.814 & 2.7459 & 3.069 & 2.902 & 2.782 & 2.995 \\
\hline 4. Once a Week & 1.771 & 2.4152 & 3.316 & 2.547 & 2.512 & 2.937 \\
\hline $\begin{array}{l}\text { 5. } 2 \text { to } 3 \text { times a } \\
\text { week }\end{array}$ & 1.663 & 2.3052 & 2.836 & 2.532 & 2.467 & 3.069 \\
\hline $\begin{array}{l}\text { 6. } 4 \text { to } 6 \text { times a } \\
\text { week }\end{array}$ & 1.600 & 2.192 & 2.856 & 2.401 & 2.557 & 3.015 \\
\hline 7. Every Day & 1.792 & 2.318 & 3.081 & 2.957 & 2.369 & 2.988 \\
\hline
\end{tabular}

Doctor visits per year is a count going from 0 to 31 . For higher numbers of visits there seem to be some recall errors as indicated by spikes in the data at 10,15 , and 20 visits. To deal with this problem the data was censored at 6 visits so that all doctor visits more than 6 are coded as 6 . Instead of using a zero inflated or hurdle count distribution which is the usual vehicle for analyzing doctor visits6, an ordered probability model was used7. Because of the censoring the highest category is visits of at least 6 . With the additional threshold parameters this model always produced much larger likelihood values and was overwhelmingly preferred to the conventional count models on the basis of the Bayesian information criterion and goodness of fit. In all models at least two latent classes were required.

\section{RESUlTS}

Table 1 shows that doctor visits decline with the frequency of drinking alcohol to the category of 4 to 6 times a week. For example, male respondents in the age group 3049 who did not drink in the last 12 months had 56\% more doctor visits than those who drank 4 to 6 times a week. This difference is highly significant but there is no significant difference in doctor visits over the bottom 3 categories. The second table tells a similar story except that drinking every day minimizes doctor visits. These results are from the latent class ordered probability models which include education, smoking status, body mass index and marital

${ }^{6}$ See Deb and Trivedi (1997), Winkelmann (2007), and McIntosh (2014b) and the references cited there

These two variables represent ordered categorical responses. The responses are coded as integers, 1 to 5 or 1 to 6 , but regression analysis is not appropriate since the probabilities of these outcomes do not evolve linearly as the integer representation would require. An ordered probability model is the correct method to be used here. See Greene $(2008,831)$ for a discussion of the method. status as regressors in addition to the alcohol frequency dummies. Only the alcohol variable coefficients were allowed to vary across latent classes. There are 7 alcohol frequency dummies and consequently 7 pairs of regression coefficients $(\alpha, \beta)$ for them. In the first row of Table 2 the regression coefficient is $\gamma_{7}=p \alpha_{7}+(1-p) \beta_{7}$ which is the average coefficient for every day (category 7 ) drinking males over the two latent classes where $\mathrm{p}$ is the probability if being in latent class 1 . This has the value -0.284 and is the smallest of the alcohol coefficients, indicating that drinking every day minimizes the number of doctor visits for males in this age group. The number to the right of it, 251.8, is the number of grams per week that males in this age group who drink every day say they consume. As noted earlier, some caution should be used in dealing with the actual amount of alcohol consumed. For males in this age group who said they drank every day there was information on their alcohol consumption for only $57 \%$ of them and it is not clear whether this is a representative sub-sample.

The results for self-reported health are similar. The regression coefficients are larger and positive since drinking leads to perceptions of better health but are characterized by slightly lower optimal frequencies.

TABLE II: OPTIMAL FREQUENCY OF DRINKING BY GENDER AND AGE GROUP FOR DOCTOR VISITS AND SELF-REPORTED HEALTH. STANDARD ERRORS ARE IN ROUND BRACKETS.

\begin{tabular}{|c|c|c|c|}
\hline $\begin{array}{l}\text { Age } \\
\text { Group }\end{array}$ & $\begin{array}{l}\text { Optimal } \\
\text { Frequency }\end{array}$ & $\begin{array}{c}\text { Regression } \\
\text { Coefficient of } \\
\text { Drinking }\end{array}$ & $\begin{array}{l}\text { Alcohol Consumed } \\
\text { (Grams/Week) }\end{array}$ \\
\hline \multicolumn{4}{|c|}{ Males } \\
\hline \multirow[b]{2}{*}{$30-49$} & Every Day & $0.284(0.062)$ & 251.8 \\
\hline & $\begin{array}{c}2 \text { to } 3 \text { times } \\
\text { per week }\end{array}$ & $0.247(0.042)$ & 106.1 \\
\hline \multirow[b]{2}{*}{$50-69$} & Every Day & $0.246(0.037)$ & 222.0 \\
\hline & $\begin{array}{l}4 \text { to } 6 \text { times } \\
\text { per week }\end{array}$ & $0.417(0.038)$ & 146.3 \\
\hline \multirow{2}{*}{$70+$} & $\begin{array}{c}2 \text { to } 3 \text { times } \\
\text { per week }\end{array}$ & $0.210(0.041)$ & 63.7 \\
\hline & $\begin{array}{l}4 \text { to } 6 \text { times } \\
\text { per week }\end{array}$ & $0.574(0.113)$ & 123.5 \\
\hline \multicolumn{4}{|c|}{ Females } \\
\hline \multirow{2}{*}{$30-49$} & $\begin{array}{l}4 \text { to } 6 \text { times } \\
\text { per week }\end{array}$ & $0.025(0.063)$ & 123.3 \\
\hline & $\begin{array}{l}4 \text { to } 6 \text { times } \\
\text { per week }\end{array}$ & $0.525(0.071)$ & 123.3 \\
\hline \multirow{2}{*}{$50-69$} & Every Day & $0.252(0.039)$ & 157.1 \\
\hline & Every Day & $0.681(0.038)$ & 157.1 \\
\hline \multirow[b]{2}{*}{$70+$} & Every Day & $0.141(0.042)$ & 130.9 \\
\hline & $\begin{array}{l}4 \text { to } 6 \text { times } \\
\text { per week }\end{array}$ & $0.599(0.059)$ & 86.0 \\
\hline
\end{tabular}

\section{DISCUSSION}

The purpose of incorporating latent classes into the models was to allow for the possibility of unobserved differences between current and life-time alcohol consumption. This turns out not to be the most compelling reason for doing this. Consider the male age group 30-49. The first latent class has significantly negative coefficients associated with the alcohol dummies. $\mathrm{p}$ is 0.85 so most of the respondents are associated with this class. However, the other latent class which corresponds to the remaining $15 \%$ of the age group, has respondents whose coefficients are positive which means that alcohol consumption leads to more doctor visits than other non-drinkers. There are 
plausible scenarios which are consistent with this outcome. The second latent class could represent former heavy drinkers who still have higher medical needs even when their consumption has declined. It could also represent late starters for whom drinking leads to problems for the same reasons that lead them not to drink in the first place. What is more likely is that there are just different types of drinker. Some respond well to drinking; others do not. Assuming that all respondents react to alcohol consumption in exactly the same way is far too restrictive as assumption. There are unobservable individual characteristics which affect how respondents react to alcohol so that two individuals whose observable behavior and characteristics are identical do not have to respond in the same way because there are unobservable factors at play.

There is another issue involving unobservables and the distinction between former drinkers and never drinkers in the non-drinking category. This issue has been raised by Fillmore et al (2006) and other researchers who were concerned that the presence of former drinkers in the nondrinking category, sometimes referred to as 'sick quiters', could be responsible for the often found positive results associated with moderate alcohol consumption.

While latent classes are of no help here and the 2013-14 CCHS has no data on former drinkers the 2005 survey does contain this information. In McIntosh (2008) it was shown that this distinction had no effect on the results and that there was no substance Fillmore et al claim that classification errors invalidated the large body of research which associated moderate alcohol intake with lower heart disease mortality. Using the 2005 data lead to no changes in the Table 2 results when the category former drinker was added to the frequency list leaving never drinkers as the new residual category.

The measure of alcohol use has traditionally been a quantity like grams per day or week. Here a frequency measure was used. This appears to work as well or better than the quantity of alcohol consumed. Consider, for example, the male age group $70+$. They drink on average 63.7 grams of alcohol per week and the regression coefficient associated with this category is $-0.210(0.042)$ and is not significantly from the regression coefficient 0.143 for drinking every day but every day drinkers drink more than $2 \frac{1}{2}$ times as much alcohol and yet only have $8 \%$ more doctor visits. It is clear that alcohol consumed per day or week is rather imprecise as a measure of alcohol use. It means that the distinction between what the Wood study recommends as desirable consumption and the current alcohol guidelines of 1-2 drinks per day for women and 2-3 drinks per day for men is not significant.

There is another feature of the procedure based on frequencies that needs to be mentioned. In Table 24 of the 6 age gender categories show drinking every day as the behavior that minimizes doctor visits. In the literature on optimization this is known as a corner solution. That means that in the case of males ages 30-49 that 251.5 grams per week does not necessarily minimize doctor visits. The optimal amount could actually be higher and possibly much higher.

\section{CONCLUSIONS}

When it comes to determining the costs and benefits of alcohol use everyone who drinks should be considered in the analysis. It is also clear that not all health measures can be applied to all age groups. The Wood study focuses on length of life and how this is affected by alcohol use. In addition, it makes inferences about what younger age groups should do based on results which are questionable and in addition are based on a much older set of cohorts and a different representation of individual welfare. This is problematic. It is clear that the men and women in the age group 30-49 respond differently to alcohol consumption than the $70+$ age group for doctor visits and self-reported health and the policy prescription is based on length of life. This is not appropriate for younger cohorts since there are very few deaths in these cohorts.

To sum up, the results from the Wood study are not convincing. It produces no credible evidence that current drinking guidelines need to be revised downward. It ignores important criteria that should be included in the determination of how much should individuals drink. If the Wood recommendations were followed Canadians and most likely many other nationalities would visit their doctor more often, be more susceptible to diseases like diabetes, heart disease, and stroke and generally feel less well. They might or might not live as long but their quality of life would be worse.

\section{ACKNOWLEDGEMENT}

An abridged version of this article was published on line under the title "The Lancet Won't Publish Data Challenging Its Puritanical Stance On Alcohol" by The American Council on Science and Health on May 31, 2019. Editorial assistance from Alex Berezow is gratefully acknowledged.

\section{REFERENCES}

Baer, H. J., Glynn, R. J., Hu, F. B., Hankinson, S. E., Willett, W. C., Colditz, G. A., ... \& Rosner, B. (2011). Risk factors for mortality in the nurses' health study: a competing risks analysis. American journal of epidemiology, 173(3), 319-329. https://doi.org/10.1093/aje/kwq368.

Baliunas, D. O., Taylor, B. J., Irving, H., Roerecke, M., Patra, J., Mohapatra, S., \& Rehm, J. (2009). Alcohol as a risk factor for type 2 diabetes. Diabetes care, 32(11), 2123-2132. https://doi.org/10.2337/dc09-0227.

Buelens, J.W.J, Y.T. van der Schouw, M.M Bergman et al (2012). Alcohol consumption and the risk of type 2 diabetes in European men and women; influence of beverage type and body size The EPIC-InterAct Study. Journal of Internal medicine 272: 358-370. https://0-doiorg/10.1111/j.1365-2796.2012.02532.x

Bergmann, M. M., Rehm, J., Klipstein-Grobusch, K., Boeing, H., Schütze, M., Drogan, D., ... \& Boutron-Ruault, M. C. (2013). The association of pattern of lifetime alcohol use and cause of death in the European Prospective Investigation into Cancer and Nutrition (EPIC) study. International journal of epidemiology, 42(6), 1772-1790. HTTPS://DOI.ORG/10.1093/IJE/DYT154.

DiCastelnuovo A, Castanzo S, Bagnardi V, Donati MB, Iacoviello L,de Gaetano G. Alcohol dosing and total mortality in men and women. $\begin{array}{llll}\text { Arch Intern } & \text { Med 2006; 166:2437- }\end{array}$ dOI:10.1001/ARCHINTE.166.22. 2437

Fillmore, Kaye Middleton, William C. Kerr, Tim Stockwell, Tanya Chikritzhs, and Allan Bostrom (2006). Moderate alcohol use and reduced mortality risk: Systematic error in prospective studies. Addiction Research and Theory Online version 1-16. DOI: 10.1080/16066350500497983 
18. Greene William H. (2008) Econometric Analysis Pearson. Prentice Hall, Upper Saddle River N.J. U.S.A.

Harriss, L. R., English, D. R., Hopper, J. L., Powles, J., Simpson, J. A., O’Dea, K., Gilea, G. G., Tonkin, A. M. (2006). Alcohol consumption and cardiovascular mortality accounting for possible misclassification of intake: 11-year follow-up of the Melbourne Collaborative Cohort Study. Addiction 102:1574-1585.

Heckman, J.J and B. Singer (1984). A Method for Minimizing the Impact of Distributional Assumptions in Econometric Models for Duration Data. Econometrica, 52, 271-320. http://www.jstor.org/stable/ 1911491.

Idler EL, Benyamini Y. (1997) Self-rated health and mortality: A review of twenty-seven community studies. Journal of Health Social Behavior 38: 21-37.

MacMinn W, McIntosh J, Yung C. 2007. How much does obesity matter? Results from the 2001 Canadian Community Health Survey. Advances in Health Economics and Health Services Research: The Economics of Obesity, 17, 333-364. https://doi.org/10.1016/S07312199(06)17013-2

McIntosh, J. (2008). Is alcohol consumption good for you? Results from the 2005 Canadian Community Health Survey. Addiction Research \& Theory, 16(6), 553-563. HTTPS://DOI.ORG/10.1080/16066350802011631 GJHS.

(2014a). Inference Problems in the Analysis of the Relationship Between Alcohol Consumption and Coronary Heart Disease. Published on line in Communications in StatisticsSimulation and Computation. https://doi.org/10.1080/03610918.2012.762385.

(2014b). Obesity and the Demand for Canadian Physician Services. Health, 6, 2624-2631. https://doi.org/10.4236/health.2014. $\underline{619301}$

-(2014c). Alcohol and Type 2 Diabetes: Results from Canadian Cross-Sectional Data. Journal of Diabetes Melitus. 4, 316-323. https://doi.org/10.4236/jdm.2014.44044.

--- (2017). Alcohol and Canadian Health. Global Journal of Health Science; $\quad$ Vol. $\quad 9, \quad$ No. 5 . HTTPS://DOI.ORG/10.5539/GJHS.V9N5P96.

Pietraszek, A. S. Gregersen, and K. Hermansen (2010). Alcohol and type 2 diabetes: A review. Nutrition, Metabolism, and Cardiovascular

Diseases 5: 366-375. HTTPS://DOI.ORG/10.1016/J.NUMECD.2010.05.001

Statistics Canada (2014). Canadian Community Health Survey, 2013 2014. [machine readable data file]. Ottawa, ON.

Wood, Angela M. Stephen Kaptoge, Adam S Butterworth, Peter Willeit, Samantha Warnakula, Thomas Bolton, Ellie Paige (2018). Risk thresholds for alcohol consumption: combined analysis of individualparticipant data for 599912 current drinkers in 83 prospective studies. The Lancet 391 April 14. HTTPS://DOI.ORG/10.1016/S01406736(18)30134-X 